\title{
Environmental Concerns and Policies in the Beijing Olympic Games
}

\author{
Liu Yang ${ }^{1}$, Honggang $\mathrm{Xu}^{2}$ \\ ${ }^{1}$ Tourism Management Department, Guangxi International Business Vocational, Nanning, 530007, \\ China \\ ${ }^{2}$ School of Tourism Management, Sun Yat-sen University, Zhuhai, 519000, China
}

Keywords: Beijing Olympic Game. Environmental Policy. Sustainability of Event

\begin{abstract}
In recent years, sustainable issues have become an interesting topic in event tourism studies. Mega events such as the Olympic Games can hardly claim to be environmentally friendly due to its large infrastructure construction to meet a short term demands. However when the environmental impacts become an important issue in the management of the Olympic Games, it turns to be an important dimension in this mega event. Greening was selected as one of the strategies during the bidding for the Beijing Olympic Games. In the implementation stage, measures were taken to promote the green issues and improve the environment in Beijing such as public campaign, reduction of air pollution, greening of the city and restructure of the urban economy. This study attempts to investigate the process of implementing the environmental policy in the Beijing Olympic Games, local understanding of the greening and the impacts of the greening theme in the 2008 Beijing Olympic Games and its potential influences on the other mega events in China. The short term and long term environmental impacts are discussed. The paper concludes that it is possible to bring some of the environmental improvements by introducing the green theme. But still mega environment can hardly adjust to the environmental impacts. However, the environmental issues caused by the mage events are still substantial.
\end{abstract}

\section{Introduction}

The impact of tourism industry on climate change is increasingly a focus of discussion and debate. More specifically, the event industry has attracted attention and there is now an increasing international debate about how to encourage the industry to become more environmentally sustainable. Although events have become an effective tool for national building, regional economic development and urban image renewal, its sustainability, especially the environmental sustainability is under debate. Events always bring good and bad, on one hand they bring us material and spiritual civilization; on the other hand, they are the deeper causes for severe environment damages, for example the huge carbon emission, air pollution, water pollution, land exploitation concomitant with the preparation and carry-out of events. All these damages have put events on an opposite position to environmental protection. During the Olympic Games, large scale of infrastructure construction and material consumption are generated to meet the operational needs of the short-term event. These two factors and environmental issues are now important parameters of the effect of mega events.

In 1970s, environment issues caused huge global attention. <Declaration of the United Nations Conference on the Human Environment $>$ was published at the first UN human environment congress in June, 1972, followed by <World Conservation Strategy $>$ in 1980; in 1987, sustainable development was revealed in < Our Common Future $>$ by the World Commission on Environment and Development (WCED), telling the competitive and cooperative relationship between human and the nature. As the biggest social event of human society, Olympic Games choose green Olympic as its best environment strategy. In 1994, <Olympic Charter> added that the Olympic Games should be held when the environment is truly concerned. Then the International Olympic Committee (IOC) firstly took 'sports and environment' as a subject for discussion in the 1994 Olympic Centesimus Annus congress, and signed the Memorandum of Cooperation with UN Environment Programme to enhance the cooperation on environmental protection between the two organizations. And later, environmental protection was listed as one of the IOC's duty by <Olympic Chapter> on July 18th, 
1996, which also stressed that the Olympic Games should be responsible for any environment issues, and should show their responsibility in their actions in order to make all related people understand the importance of sustainable development. The OIC has set up an environmental in protection committee, and formulated the <Olympic Movement!s Agenda 21> in 1999, making clear that the Olympic Games must work on boosting the global sustainable development and environmental protection, and all bidding cities must follow the strict criteria of environmental protection when organizing the event. Hitherto, environmental protection, sports, and culture become the three aspects of the Olympic spirit. However, not enough study has shed light on how the environmental missions of Olympic Game take effects. Thus, the Beijing Olympic Game may provide an opportunity.

After the reform and open policy, Chinas economy has been developing in a fascinating pace. But at the same time, the environmental problems are accumulating. In the early 1990s, the environmental issues were particularly serious and have already impacted on the living conditions of the local residents. Yet, due to strong desire for economic growth, the awareness of the environmental pollutions was weak. The environmental problems were not given enough attention by the authorities or the public yet. A misconception exists that, the western industrial development pattern - pollution first and counter-measurement taken later, was avoidable in China.

In 1992, when China failed in the bidding for the Olympic Games, Chinese people for the first time recognized the importance of environmental problems if China wanted to be a player globally. After a decades preparation, in 2001, China presented three ideas which are green Olympic, high-tech Olympic and humanistic Olympics . A series of environmental protection promises were proposed to compete for hosting the 2008 Olympic Games. The bid was a success. In the next seven years of preparation, Beijing took various effective measures to achieve green Olympic which has some long term impacts on Beijing's environment sustainable development and other mega events in China such as 2010 Shanghai Expo, the 16th Asian Games in Guangzhou.

The purpose of this paper is to investigate the impacts of the Green Olympic theme on the environmental sustainability in Beijing. Particular attentions will be paid to the formulation and the implementation of environmental policies, regulations and controls in addressing environmental problems.

\section{Literature review}

Sustainability has been the main theme in the present world. Sustainable tourism development is also the major field for the academy and human life. According to the World Tourism Organization (2001), sustainable tourism development should follow some criteria:

Sustainable tourism development meets the needs of present tourists and host regions while protecting and enhancing opportunities for the future. It is envisaged as leading to management of all resources in such a way that economic, social and aesthetic needs can be fulfilled while maintaining cultural integrity, essential ecological processes, and biological diversity and life support systems.

Although special events are often considered catalysts to tourism and regional development, negative environmental and social costs are also generated. As a result, environmental sustainability of the mage events has been major concern over the years. Recent researches have focused on how to practice events to be green. Dickson and Arcodia (2010) investigated the roles that professional associations play in promoting sustainable events and evaluated their roles in educating industry professionals on sustainable event practices. Green event could establish a sustainability policy or incorporate sustainable practices into its management and operation. Laing \& Frost (2010) provided an overview and analysis of operational issues linking to green events, including the importance of developing policies and practices in waste disposal, recycling, traffic, power and carbon offset schemes. They examined some of the challenges involved in incorporating green messages into an event theme. Collins (2007) introduced the Ecological Footprint Analysis (EFA) to understand the environmental consequences of the 2003/04 FA Cup Final.

There are also papers examining the environmental impacts and concerns of the Beijing Olympic Game. Beyer (2005) investigated the essence of Green Games of Beijing Olympic and evaluated the 
potential of Beijing Olympic Plan for China's Sustainability development. He concluded that Beijing's decision to commit to suitable development was a reaction to losing the bid to Sydney in 2000. MOL(2010) who argued that Beijing had successfully used the sustainability as the attractor to enter into the global system and sustainability had begun to play a role in the mega event.

Within the Chinese context, Researches has been conducted on the environmental protection of Beijing Olympics, and the impacts of 'green Olympics' on Beijing's environment, ecology and civilization. Dong (2001) discussed the impacts of Beijing Olympics on Beijing's sustainable development, especially on politics, culture and economy. He stated that ameliorative environmental protection, appropriate planning and utilization of energy conservative sport venues of Beijing Olympics would contribute to the sustainable development of Beijing. Xiao et al. (2003) interpreted the three themes of Beijing Olympics, and held that although Beijing Olympics encouraged a harmonious society, it still faced challenges. Ren (2005) explored the negative environmental impacts of sports events, and stated that the Olympic had advantages in environmental protection. Zeng et al. (2006) expatiated the concept of 'green Olympics', and examined its development and value on environment protection. They also analyzed the impacts of 'green Olympics' on Beijing's environment and the strategies to deal with the impacts. Fu (2007) systematically introduced the evaluation system of the health and environment impacts that the Olympic Games had on the host cities. Wu (2008) studied the impacts of 'green Olympics' on ecology and civilization from an economical perspective.

However, most of Chinese studies focus on the discussion of the meaning of the Green Olympics and the pros and cons of the Green Olympics. Empirical studies are seldom conducted to fully understand the process of the Green Olympics and its long term and short term impacts on environmental sustainability. Thus, the above issues will be addressed in this paper.

\section{Research method}

Policy analysis method is utilized in this research to explore the environmental policy making and the implementation of Beijing Olympic Games, as well as local peoples perception of 'green Olympics' and the potential impacts on other mega events in China. Both long-term and short-term environmental impacts are discussed in this study. Though mega events absolutely cause environmental problems, employing green themes in mega events and highlighting the concerns about environment in event policies can improve local environment to some extent. It is believed that event can boost the protection and improvement of local environment in the special social and economic context.

The policy documents and data resources in this research are from < Beijing Master Plan> (approved by the state council), the Environment communique from Beijing Environmental protection bureau, Beijing Water Authority, Beijing Gardens Bureau, Beijing Development and Reform Commission, Beijing Olympic Games official website, Beijing Committee of Science and Technology, and Press Conference. The study focuses on the air pollution which was considered the most serious and causes deaths in Beijing, rather than addressing every aspect of the environmental issues.

The documents are drawn from various bureaus, in an attempt to demonstrate that the environmental actions are well integrated into the policies and plans from all the institutions and not only limited to the EPA.

\section{The process of environmental policy and implementation}

\section{The failure of the application for Olympic Game in 1992 and the resubmission}

The Chinese has developed a strong complex with Olympic Games, a complex which is very much associated with modernity and the regaining of the confidence in the world again after many defeated records since 1840. In 1932 Chinese people firstly attended the Olympic Games, and to the Berlin Olympic Games in 1936 and London Olympic Games in 1948, no Chinese ever fought into to the 
final. The Chinese began to realize that wars and weak economy makes weak sports. In 1984 Los Angeles Olympic Games Chinese finally took back home 15 pieces of gold. And it is the new time for Chinese sports. In 2001, the OIC evaluation indicated that there were $96 \%$ Beijing local people who supported Beijing to bid for Olympic Games host city. When Chinese athletes brought home 32 pieces of gold at 2004 Olympic Games, Chinese people were so excited for 2008 Olympic Games. Through Olympic Games, an international mega sports event, China can show what she has achieved in her reform. And the Beijing Olympic Games is the best stage to present Chinese peoples full passion.

When China initially bid for the Olympic Games in 1993 and failed with national sorrow, the government realized that besides economic growth, environment development and human rights are important criteria for the jury board. China has to construct the similar value to obtain a world event. The impetus for Beijing to make sustainable development a major component of the Olympic bid was rather a reaction to losing the desired 2000 Olympic Games to Sydney.

In the 1990s, the environmental issues received limited concerns nationwide. The city air quality in China deteriorated whilst the economy and urbanization accelerated. A study which compared the air quality in 157 cities of 45 countries found that the air pollution composite index of Beijing was ranked 7th in 1995 and 3rd in 1998, among the worst in the world, where had 35\% higher suspended particles and 62\% higher sulfur dioxide than the Mexico city, the most polluted city in the world. This number reached the highest level in the history. From 2001 to 2005, on average, 15 serious polluted days were recorded each year, taking up $4.1 \%$ of the whole year.

To bid for Olympic Games, environmental problems ran up to the top of the governments agenda. The government proposed 'green Olympics' as the main theme of the three Olympic themes in the Beijing Olympic Action Plan highlighting 'green Olympics' as the priority in the planning and construction of Olympic infrastructure. Aims were set to strictly follow the eco-environment standard, to employ a broad range of environmental protection techniques, to improve environment in a large scale, to boost the 'green' process of city and village, to enhance the industry of environmental protection, to enhance peoples' awareness of environmental protection, to encourage green consumption behavior, to encourage activities related to environmental protection, to improve the environment of Beijing and to build eco-city. It encouraged a healthy way of living, and is supposed to reach a harmonious relationship between human and nature. When Beijing bid for Olympic Games in 2001, the government promised that 1) the city would monitor sulfur dioxide, carbon monoxide, nitrogen dioxide, and inhalable particulate every day; 2) the city would improve the air condition; 3) during the Olympic Games, four main pollutants index will reach the national standards and the World Health Organization standards, in order to provide a good air condition to the Olympic Games.

Beijing Olympic Games is considered to be the milestone of China's modernization. After the successful bidding, Beijing started a series of environmental protection work and made 'green Olympic' into reality. Beijing Olympic Games also became a catalyst in boosting the environmental sustainable development of Beijing.

According to Beijing Master Urban Planning (2004 2020), 2008 is the beginning of the development of eco-city, and 2020 is the maturity of the development of eco-city. 'Green Olympic' creates an important chance for improving environment and the civilization of China.

\section{Formulation and Implementation of long-term and short-term environmental policies}

There are two sets of policies. One is the long term-strategic plans and policies. It can be seen that environmental issues is not only the responsibility of the environment protection agency. It is integrated with the overall social and economic plan and therefore it is the issue for all the institutions.

According to the objectives and principles set by < Beijing Master Urban Plan (2004 2020) > and < Outline of the Eleventh Five-Year Plan of the National Economy and Social Development>, the government decided to make plans for environmental protection and eco-environment development in the 'eleventh five-year period', together with plans for energy development and energy conservation, and plans for recyclable in order to settle the problem of population growth, economy development, the relationship between resource utilizing and environmental protection. 
These policies and strategies were envisaged to solve the problems of environment, to enhance the carrying capacity of resource and environment, and to make cities suitable to live.

The other was formulated mainly for the period of Olympic Event. In 2002, according to < Olympic Charter $>$, < Host City Contract for the Games of the XXIX Olympiad $>,<$ Bidding report $>$, $<$ Outline of the Tenth Five-Year Plan of the National Economy and Social Development $>$ and other documents, the government came up with <Beijing Olympic Games Action Plan> , which directed the preparation of Beijing Olympic Games in the following seven years. This plan was about strategy and objectives, including five parts: total strategies, sports venues and relative construction, environment and city infrastructure construction, social environment development and strategic supporting measures.

These two kinds of plans are overlapping, indicating that at least the Beijing Olympic act as a catalyst toward sustainable development. It can be defined as long-term and short-term.

\section{Key long-term practices}

- Restructuring economic sector

In 2000, the added value of the primary, secondary and tertiary industry consisted of $3.63 \%$, 38.06\% and 58.31\% in GDP respectively in Beijing . The Urban Master Plan clearly stated that Beijing would make efforts to restructuring its economy from secondary to the service industry (source from: Report of Energy Consumption and the Energy Saving in Beijing in the Ninth Five-Year Plan). The preparation phrase for the Olympic Games was also within the third phase of industry restructure of Beijing. During this phase, the upgrade process of the whole industry accelerated, and the high-tech industry developed dramatically as well. Although one can argue that Beijing would go through this restructuring even without the Olympic Game in the long run, the Olympic Game indeed accelerated this process. The most effective one was to relocate the heavy industry which produced heavy pollution. More than 200 polluting factories were moved out of Beijing, especially the Beijing coking plant, and Shou Gang Iron \& Steel Group 'Urbanized' modern agriculture and industry are developing in a fast pace. The finance, wholesale \& retailing, culture \& innovation, IT, computer science, software, high-tech and service industry grew fast. In 2007, Beijing Development and Reform Commission published <Guidance and comments of the adjustment of industry structure in Beijing $>$ and $<$ Decision on developing recyclable economy and conservation oriented cities $>$, which made reclaimed the objectives of the industry restructure, including aims to develop modern service industry, high-tech industry, modern manufacturing and modern agriculture, to improve innovation, to change the development pattern of economy, to adjust the structure of industry, to optimize space distribution, to enhance integrated competitiveness, and to improve the service ability of city (Beijing Development and Reform Commission , < Guidance and comments of the adjustment of industry structure in Beijing $>,<$ Action plan of expediting the development of recyclable economy and environmental friendly cities> were also implemented in Beijing in the following four years.

\section{- Adjust energy structure}

The government aims to optimize the structure of urban energy by introducing and developing clean energy such as natural gas and electricity etc, improving the structure of the supply of power, enhancing the construction of power grid in the central district of urban, improving village power grid; increase the security of the supply of power; developing and utilizing new energy such as geothermal energy, solar energy, wind energy and biomass energy and developing energy conservation campaign. The $<$ Plan of adjusting energy structure of Beijing $>$ issued by the Beijing government in 2001, set up the short-term (2005) and long-term (2010) objectives, planning scheme and measures of the adjustment plan of energy structure in Beijing. This plan was based on the study of consumption, environmental protection and economy development, predominately aiming to plan for the best development of energy. The Beijing Development and Reform Commission issued $<$ Implementation plan for enhancing energy saving in Beijing > and <Measures of supervising energy saving in Beijing> in 2007, which made clear the priorities of energy saving. The structure of a variety of energy consumption was optimized, and coal was replaced by electric power and natural gas as main consumptive energy (see Figure 2A, 2B). From 2001 to 2007 in Beijing, the proportion of good 
quality energy in the total energy consumption rose from $68.8 \%$ to $79.6 \%$. It is estimated that the number will rise to around $83 \%$ in 2010.

- Change the structure of urban land use

According to < Master plan of Beijing urban>, the Gardens Bureau of Beijing aims to develop three green ecological barriers which are mountainous area, plain area, and urban isolated green area to prevent the sands from the northwest of China. From 2001 to 2008, the forest green rate of Beijing rose from $41.9 \%$ to $51.6 \%$, and the mountain forest green rate increased from $57.23 \%$ to $70.5 \%$. An ecological shelter forest belt over $1000 \mathrm{~km}$ long and 25 thousand hectare is constructed and a green belt of 12.6 thousand hectare is built. The area of nature reserve reached $8.2 \%$ of the total land area in Beijing, which makes the 'green Olympics' into reality.

- Improve local people's awareness on environmental protection

Initiatives were also carried out to increase the environmental awareness and the participation in the environmental protection among the public. A campaign of ecological civilization was launched to educate people to choose green products and cultivate environmental friendly consumption habits. It also effects in improving local people's awareness on environmental protection, developing green community, green shops, green campus, green companies and green organizations, advocating recycled products in family and company, enhancing people's awareness on scarce water resource, regulating the water rate system, employing water-saving technologies, promoting water-saving appliance, encouraging water-saving in the whole society, installing water-saving and energy-saving equipments, implementing separate waste collection, promoting ozonosphere protection equipments, and advocating public transportation .

The Olympic Games is the most popular event with the largest number of participants. It is granted a refined social image and social charisma. Hence, its impact on environmental protection is widely spread. The objective for 'green Olympic' is not only to optimize and green the natural environment of the city, but also to transform the mentality for cooperation between the Olympic Games and environment, people's value on environment and their behaviors. By participating in the Beijing Olympic Games, local people are aware of the changes of the environment, and understand the importance of environment. It is reported that the Beijing Olympic increases local people's perception of happiness. Moreover, 3,032 telephone interviews conducted by Beijing public opinion survey center reveal that $91.9 \%$ people pay attention to environmental protection after the campaign of Olympic Environment Protection.

- Readjust the Transportation system

The rapid urbanization and economic development perplex the traffic condition in Beijing. In 2004, Outlines of Beijing Transportation Development was issues to develop and improve the attractiveness of the public transportation system. Rapid transportation system was given priority to the Olympic Game in 2008. Price of the public transportation was also reduced in 2007 and 2008. For the first time in 2008, the ratio of passengers using public transport exceeded that of the private vehicle (Mao, et al, 2008).

\section{References}

[1] Dickson, C., Arcodia, C.(2010). Promoting sustainable event practice: The role of professional associations International Journal of Hospitality Management, Volume 29(2), Pages 236-244.

[2] Collins et al.. (2007). Assessing the environmental Consequences of Major Sporting Events: The 2003/04 FA Cup Final, Urban Studies 44 (3) Pages 457-476. 